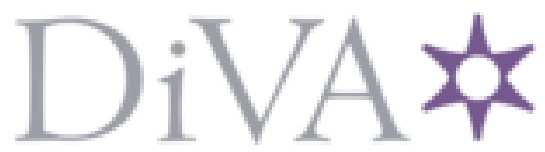

http://www.diva-portal.org

This is the published version of a paper published in International Journal of Innovation Science.

Citation for the original published paper (version of record):

Rundquist, J., Emmitt, S., Halila, F., Hjort, B., Larsson, B. (2013)

Construction Innovation: Addressing the Project-Product Gap in the Swedish Construction

Sector.

International Journal of Innovation Science, 5(1): 1-9

https://doi.org/10.1260/1757-2223.5.1.1

Access to the published version may require subscription.

N.B. When citing this work, cite the original published paper.

Permanent link to this version:

http://urn.kb.se/resolve?urn=urn:nbn:se:hh:diva-21607 
Construction Innovation: Ad dressing the Projech-Product Gap in the Swedisth

Construction-Sertor

by

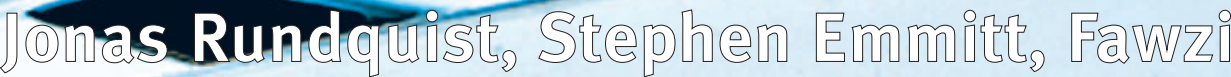

આalila, Bengh njom, Bengh Larsson

reprinted fron

Interpanonat fotrpal of

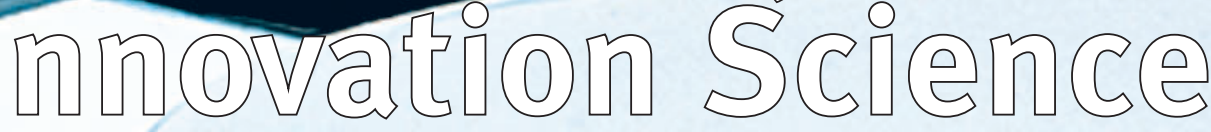

\section{Volume $5 \cdot$ Number $1 \cdot$ March 2013}

Multi-Science Publishing

1757-2223 


\title{
Construction Innovation: Addressing the Project-Product Gap in the Swedish Construction Sector
}

\author{
Jonas Rundquist ${ }^{1}$, Stephen Emmitt ${ }^{2}$, Fawzi Halila ${ }^{1}$, Bengt Hjort ${ }^{1}$, Bengt Larsson ${ }^{1}$ \\ ${ }^{1}$ Halmstad University, School of Business and Engineering, Sweden \\ ${ }^{2}$ Loughborough University, School of Civil and Building Engineering, UK \\ Jonas.Rundquist@hh.se; S.Emmitt@lboro.ac.uk; Fawzi.Halila@hh.se; \\ Bengt.Hjort@hh.se; Bengt.Larsson@hh.se
}

\begin{abstract}
The construction sector is often accused of being inefficient, conservative and noninnovative, although some commentators have suggested that the construction sector is not backward, it is merely different to other industries. One of these differences is the uniqueness of construction projects, which are determined by the characteristics of the site, interaction of project participants (also partly site specific) and the relationship between contractors and building product producers (which changes from one project to another). These factors are known to colour construction innovation. Previous research into the Swedish construction sector has identified a significant gap between the building product producers who are 'product focused' and the contractors who are 'project focused', with concerns expressed about effectiveness of communication between two. The findings of previous research imply, both implicitly and explicitly, that this gap may be hindering innovation within the construction sector. This appears to have implications for those concerned with construction, the building users and society as a whole. In this paper the authors provide an extensive review of the literature and research findings from which a number of unique insights are offered. The reasons for the gap between producers and contractors are discussed and a number of innovative measures are proposed that may help to bridge the gap, and hence improve innovation systems. The paper concludes with some practical findings for producers and contractors as well as some thoughts on where future research should be targeted.
\end{abstract}

\section{INTRODUCTION}

Innovation is necessary if firms, regardless of sector, are to survive and prosper in a competitive marketplace $[1,2,3]$. The construction sector is often portrayed as being inefficient, conservative and non-innovative; it is a constant feature within the construction literature leading to calls for doing things differently (see for example Akintoye et al., [4]. Although some have argued that the construction sector is not backward, but different, especially when compared to other industries; and this affects the context of innovation (see for example Ball [5]). One of these differences is the uniqueness of each construction project, which is determined by the characteristics of the site, the interaction of project participants (mostly site specific) and the relationship between the contractor and the building product producers. These relationships are different with each and every project. While construction projects are characterized as temporary undertakings, geographically specific and constrained by time, the suppliers of the materials, building components and building systems - the building product manufacturers/producers - are characterized as traditional industries (i.e. not temporary, serving a large geographical market, and producing continuous runs of products).

Previous research into the Swedish construction sector has identified a significant distance between the building product producers who are 'product focused' and the contractors who are 'project focused', implying a product-project gap $[6,7,8,9,10]$. The research also expressed concerns about the effectiveness of communication between these two groups [6], which have different mindsets and cultures. The contractors are process orientated and the building product producers are product orientated [7]. The findings of previous research also imply, both implicitly and explicitly, that this gap may be hindering innovation within the construction sector $[8,9,10]$. It is, however, unclear from the 
literature whether this is a situation peculiar to Sweden, since other research into the relationship between the producers and the contractors has not focused on this area (see for example Emmitt \& Yeomans [11] for a comprehensive overview), indicating a gap in the research. At a national level, and perhaps at an international level, this challenge appears to have implications for those concerned with construction, the building users and society as a whole. More specifically, it is possible to speculate that the communication gap may be linked to the ineffective flow of knowledge and limited knowledge integration. The challenge is twofold, namely that:

a) Contractors (construction projects) lack a structure to absorb ideas from the people engaged in projects and hence may fail to elaborate these ideas into needs, and

b) Building product producers lack a system to get access to these needs as the construction projects are dissolved after completion of a project.

In this paper the authors address these two challenges by providing a review of the literature and research findings, from which a number of unique insights are offered. Reasons for the gap between building product producers and contractors are discussed and some innovative measures are proposed that may help to bridge the communication gap, and hence improve knowledge integration, and hence enable innovation within this sector of the Swedish economy.

\section{SETTING THE SCENE}

\subsection{Construction - A Relay Race}

The construction process starts with an idea or a need for a new building or artifact. Then a chain of consecutive and sometimes overlapping phases follows; Program phase, design phase, procurement, production phase, and project delivery. Every phase has its main performers and its delivery package a program, a drawing or a finished activity in the project. The project team consists of a purchaser (client), a design team (architect and engineers) and a production team (general contractor and subcontractors). Every actor in the team has its package (baton) to deliver to the next actor in the chain (athlete), hence the comparison to a relay race.

The construction sector comprises a multitude of occupations, professions and organizations $[12,13,14]$. The client employs consultants such as architects and engineers to design the project. A general contractor or main contractor is selected to construct the project according to the design. The general contractor will employ its own subcontractors as well as other subcontractors, which may be named or nominated by the client. Building product producers will supply the required materials either to the general contractor who hands them to the subcontractors to fix and install, or directly to the subcontractors. Although some of the very large contracting organizations have established supply chains with a small number of producers, for example producers of windows, it is still common within the sector for the designers to specify the products and then for the contractors and sub-contractors to select different suppliers for each project. Therefore, there are few established supply chains, compared to manufacturing industries such as car production. This creates challenges for effective knowledge transfer.

Two prominent characteristics of the relay race are the organization of the production work force into a variety of trades and the practice of subcontracting portions of a project to special trade contractors by general contractors [15]. From a network perspective these characteristics could be described as; a) a construction project being a temporary organization and b) regarded as a strong temporary network within the larger permanent loosely coupled network of the construction industry as a whole [16].

According to Rowlinson and Walker [17] the construction industry is also characterized by its nonstandardization. Very often, products are "one-offs" and the production processes are to some extent different from each other. Hence, no universal standard or specification can be applied to the product, which leads to difficulties in quality assurance and, as noted above, it makes it difficult to maintain constant supply chains. Interviews with Swedish actors carried out by Sundqvist et al. [10] indicate that the building product producers mostly have poor cooperation with the actors in the building process. Poor cooperation often implies insufficient information about customer needs for the building product producer and, thereby, less knowledge about the market. It is also significant that research about the building sector has focused on the companies in the relay race (construction management literature) but not very much research can be found about the building product producers $[10,18]$. It would appear that 
the building product producers are not at the races.

\subsection{The Innovation System in the Construction Sector}

The actors in the construction sector constitute a very complex, and to a large extent fragmented system $[19,20]$. There has long been a belief that generic management methods such as total quality management (TQM), just-in-time (JIT), and lean production could be applied in the building sector. However, the complexity of the sector suggests that these methods could be inapplicable or even counterproductive [16]. It is important to examine the sector and its processes and actors in terms of its own demands and perspectives. The Swedish Building Commission [21] has stated that there are good reasons for developing systems and institutions to coordinate research in the sector. The decision to adapt to technological change may in many cases be difficult because many different companies are designing, producing and operating the products. A capable innovation system is crucial for the development of the construction sector, although how this is best achieved remains open to question.

Building product producers are positioned upstream of the supply chain. They develop products to be used at some point in the future by contractors to help realize a construction project. The former manufacture products which have distinct product life cycles, which Larsson [8] termed basic technology companies. Their research and development possibilities differ from the project-oriented construction companies, which have to play a system-integrator role. Larsson [7] classifies them as intermediate companies. They have intermittent business relations with the basic-technology companies; relationships are set up on a project by project basis. For the contractors, the purchasers of the products, it is often initial cost rather than innovation, that is foremost in their mind and which colors their business relations [6]. The word intermediate also refers to the fact that the contractor is positioned between the client and the producer of the building products. The client will be paying for the building, but will not purchase building products directly; instead these are specified by designers and engineers and then purchased from the building product producers by the contractor and sub-contractors. There is an intermediary (the contractor) between the client and the building product producers. Although the building product manufacturers engage in product innovation [22,23], their relationship with the contractors and designers is rather fleeting and often a result of chance rather than foresight.

A general innovation process is often described as a sequential process starting with idea generation and ending with the diffusion of the innovation [24]. If we look at the roles of the basic technology companies and the intermediate construction companies and overlay their impact on the innovation process model, we obtain, according to Larsson [7], the model shown in Figure 1. Here we notice that it is vital to the innovation process that the intermediate construction companies are connected to the basic technology companies at the idea-generating phase. Intermediate companies must be connected to basic-technology companies to communicate what new products they think need to be developed for the building process.

The conclusions that can be drawn from this model are three-fold in terms of innovation;

1) The intermediate construction company must develop its ability to adopt and apply many very different basic technologies,

2) The basic-technology company must develop its ability to be informed as to what technologies must be developed, and

3) It is essential that communication in both directions is functioning between the intermediate construction company and the basic-technology company.

\subsection{Building Product Producers - The Basic Technology Companies}

The Swedish building product sector is large and characterized by diversity, comprising a wide range of manufacturers and products. Manufacturers range from small manufacturing concerns to large multinational companies. Similarly materials and products range from basic aggregates and timber products to very sophisticated service systems. The total output of the Swedish building material sector is approximately $3 \%$ of the Swedish GNP or SEK 110 billion (approximately $£ 8$ billion). The sector consists of 3300 companies with approximately 60,000 employees. Building components represent around $40 \%$ of the total cost for a normal multi-storey residential building [25] and the sector is collectively the largest single contributor to construction projects and important for the country in general. However, the sector is not seen to be important by the construction companies or by researchers in construction management [8]. 


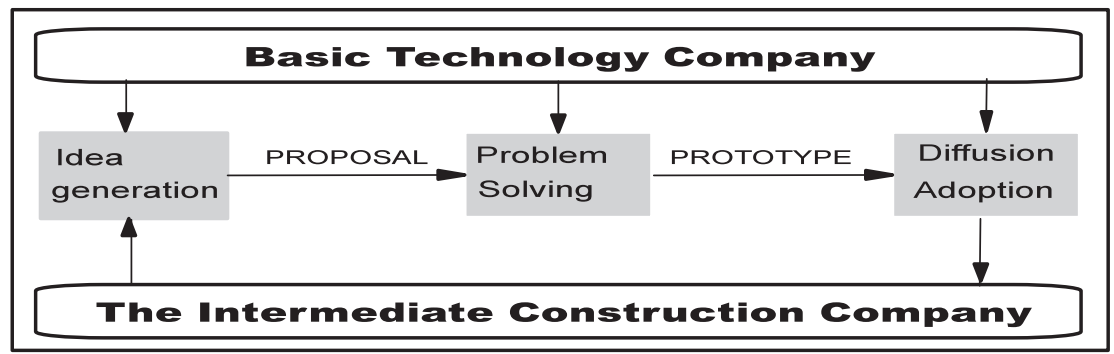

Figure 1. The impact of the basic-technology company and the intermediate company on the innovation process [7]

Building product producers -the basic technology companies - are often referred to as a single group, which can be misleading. This 'group' is engaged in a complex set of operational activities that are specific to each type of product and producer, be it the production of bricks, timber cladding or thermal insulation products. A categorization of the producers can, therefore, be of help in understanding their characteristics; and the potential for new product development varies greatly, as do their scales of production, economy, degree of specialization, amount of prefabrication etc. In some cases, the manufacturer-buyer relationship is more or less standardized, needing no specific product or service adoptions. Such relationships are examples of low-involvement relationships. High involvement relationships, on the other hand, are required where the products are subject to some uncertainty, which implies increase in relationship and supply handling costs. A categorization of suppliers, thus, helps in finding out where the low and high relationships are most likely.

Table 1 shows the main building product producers in a matrix with two categories: Standard Items and Order Production on the horizontal dimension, and Bulk Items/Materials and Components/Elements on the vertical. Standard items are produced without a specific address for assembling (non-project specific). Order-produced component/materials are made to order and are project specific (i.e. they rely on a contractor placing an order). The bulk items/materials consists of raw material with a relative low level of processing, while the processing in the components/elements category results in a higher degree of mix of materials and function [26].

Table 1. Grouping the Production of Building Materials [26]

\begin{tabular}{lll} 
& Standard Items & Order Production \\
\hline Bulk Items and Materials & $\begin{array}{l}\text { 1.Cement, wood, electrical cables, } \\
\text { insulation materials, plaster boards, tiles } \\
\text { and bricks (material production) }\end{array}$ & 2. Premixed concrete \\
\hline Components and Elements & $\begin{array}{l}\text { 3. Windows, doors, skylights, sockets, } \\
\text { kitchen components (component ) } \\
\text { production }\end{array}$ & $\begin{array}{l}\text { 4. Prefabricated toilet rooms, concrete } \\
\text { elements, wood elements, windows- and } \\
\text { facade elements (element production or even } \\
\text { system production) }\end{array}$ \\
\hline
\end{tabular}

\section{ADDRESSING THE INNOVATION GAP: A LACK OF KNOWLEDGE INTEGRATION}

Our problem statement is that there is a missing link between the two groups of companies (see figure 1), which is a lack of knowledge integration. Poor communication between the construction industry and the building product producers have been pointed out by some authors $[6,27]$ as an explanation as to why the building material producers have fragmented and vague information as to the needs of the construction companies. Moreover, the building product producers appear to have problems assimilating information that would give them relevant innovation ideas. Communication gaps between the basic technology companies and the intermediate construction companies may cause difficulties in determining which products to develop, which products to improve, and the way in which they should be improved [10]. In other words, they have different business logics and they have difficulties determining what products should be developed and how existing products should be improved. In an extensive excellence study on manufacturing companies Sundqvist [9] presented a comparison between two industry groups - the "Building Material Suppliers" and the "Other Manufacturers". In this study 
he showed that the building manufacturing companies seem to have a lower level of innovation capacity than other manufacturing companies, which could partly be explained by the specific knowledge situation in the industry.

In general, the knowledge needed for the development of new products is becoming increasingly complex and distributed. Consequently, there is a need for firms to develop their capabilities for knowledge integration. Knowledge integration is defined as "the integration of complementary assets and knowledge across organizational boundaries for developing market-oriented new products, services or processes through an information-sharing and communication process" [28]. Recent research has shown that knowledge integration is an important determinant for innovation success [Rundquist, J. (2012) The ability to integrate different types of knowledge and ts effect on innovation performance, International Journal of Innovation Management, 16(1250014)]. Firms increasingly seek to integrate knowledge that is specialized and differentiated, but also complementary to what they already possess [30]. However, effective knowledge integration is a far from easy task to achieve and represents a major managerial challenge in innovation $[31,32,33]$.

Knowledge integration has been intensively studied as integration within projects [31], between projects [e.g. 34,35], and within organizations with industrial manufacturing [e.g. 36]. However, the integration of knowledge between projects (in this case temporary coalitions including many actors and organizations) and organizations with industrial manufacturing has not been in focus in previous research. These are the specific conditions in the construction industry as the construction of a building is normally a temporary coalition including many actors and organizations, but product development is mainly conducted in organizations with industrial manufacturing (the building product producers).

Knowledge integration can be organized into three main perspectives [29];

1) Knowledge integration as sharing or transferring knowledge.

2) Knowledge integration as use of similar/related knowledge. or

3) Knowledge integration as the combination of specialized, differentiated but complementary knowledge.

The second perspective could be used as the knowledge among the actors involved in the construction project and the actors involved in developing/producing the construction material mainly stem from a common knowledge base. From this perspective actors specialized in certain areas (e.g. construction industry) will more easily integrate their knowledge as they have a common knowledge base. By searching for 'small worlds' [37,38], they may therefore be able to search further into specialized applications of knowledge, such as new products. Nesta and Saviotti [39] use the term 'coherence' of a group's knowledge base as a proxy for amount of knowledge integration accomplished. This perspective contributes mainly with studies of a measured outcome rather than developed processes [29], which is of use, but will not help to elaborate the knowledge integration process per se.

It may, however, be fruitful to use the third perspective, as there is knowledge new to the building product producers needed to be integrated from the actors in the construction industry. The special knowledge developed on the construction sites is, in this argumentation, complementary to the knowledge pursued within the building product producers. Inefficiency of cross-learning is recognized in previous research [e.g. 40,31,33], which would imply that improved knowledge integration mechanisms would decrease the cost of trying to capture such knowledge.

Van de Ven et al. [41] suggested four knowledge integration mechanisms (rules and directives; sequencing; routines; group problem solving and decision making) that are suitable to resolve knowledge integration situations under different degrees of interdependence. These mechanisms are also to be supported by a base of common knowledge.

- Rules and Directives refer to 'impersonal' approaches for coordination that need "plans, schedules, rules, procedures and policies, as well as information and communication systems".

- Sequencing refers to allocation of tasks to members who have the appropriate knowledge of the task.

- Routines are a "relatively complex pattern of behavior ... triggered by a small number of initiating signals or choices and functioning as a recognizable unit in a relatively automatic fashion". Individuals only need to understand their role in the routine without the need of rules and directives. 
- Group problem solving and decision making: relies on methods which are characterized by high communication. It allows combining knowledge which was previously distributed among various actors in order to solve a problem.

The first three mechanisms target efficiency of integration by avoiding costs for communication and learning. The fourth mechanism may require integration through more personal and communicationintense methods. According to Demsetz [42], rules and directives as well as sequencing and routines can support integration of knowledge while maintaining specialization and also economizing on knowledge transfer. However, these mechanisms appear to be limited in flexibility. In addition to this Grant [43] pointed out that: "While these mechanisms for knowledge integration are necessitated by the individuals' stocks of specialized knowledge, all depend upon the existence of common knowledge for their operation" [43: p.115]. This means that building product producers and actors in construction projects must have some common knowledge in order to understand and be able to integrate the knowledge from the other part. It is a probable assumption that this common knowledge exists, or is possible to build, as all actors are parts of the same permanent loosely coupled network of the construction industry as a whole [16].

\section{DISCUSSION AND CONCLUSIONS}

In reviewing the literature is has become clear that there is a very small body of research into how building product producers interact with contractors and sub-contractors. The work that has been published indicates difficulties in communication and in knowledge integration, which not only has implications for innovation but also for the longer term competitiveness of the Swedish building product producers. Research into this relationship, the temporal supply chain, may provide valuable information for the building product producers and the contractors, helping to bring about a better understanding of one another's particular stance; and hence help to facilitate a closer and more innovative working relationship. In this section we will first discuss two major challenges to achieve innovation through knowledge integration in the building industry. After that we will discuss possible solutions in the form of knowledge integration mechanisms distinguished from the literature.

\subsection{Major Challenges}

Two major challenges can be found. These are: 1) the structural dysfunction in the interface between the short term construction projects involving temporary staff from multiple actors which dissolve after finalizing the project and the long term building product industry with continuous production in an industry setting, and b) the cultural differences between the project and product focused actors.

\subsubsection{Project vs. Process}

The relation between the staff engaged by the construction company at the site and the staff developing new products at the building product producer is very loose, one might argue non-existent. The purchase of the products is normally made as a framework contract between the HQ of the construction company (via purchasers) and the building product producers. Orders are then delivered to the site to an agreed schedule, made by the building product company's own truck or by an independent transporter, but in either case there is no natural interface between the staff involved in product development and the staff at the actual site. Neither there are any formal contacts between the site and the building material supplier at the operational level. This means that there is a low probability that any formal mechanisms can be implemented.

Staff involved at the construction site will be redeployed and dispersed to new projects after completion of the current one. This leads to a situation where most problems are taken care of in a pragmatic, but not always effective way, where organizational learning is low. That is, the problem is solved for this project, but the knowledge about the problem (leading to an idea for a new or improved product) and the organizational learning (developed processes to avoid the problem in the future) disappears, as the staff around a specific construction project is re-organized for the next project. The challenge is how to: a) get hold of ideas appearing among staff at the construction site, and b) store the collective knowledge developed at a site for future projects.

\subsubsection{Cultural differences}

Cultural differences exist between the contractors and the building product producers; and this cannot be ignored when looking at communication, knowledge transfer and innovation. Both groups will have 
their own innovation cultures, coloured by their industrial sector and their process or product focus. These differences not only lead to different mind sets (seeing the construction sector quite differently from one another), but also result in different languages, values, beliefs and goals; which may be linked to a national culture [44,45]. Addressing cultural norms through some of the initiatives proposed below may help to expose some of the differences; which can then be addressed with appropriate interventions at the building product producer level and at the contractor level via construction projects.

\subsubsection{Solutions through use of knowledge integration mechanisms}

The lack of formal connection between the construction site and building product producer makes it hard to use rules and directives, sequencing and routines. These levels of knowledge integration mechanisms require the power to implement mandatory actions among the staff. Routines may offer some potential, if there is a possibility to implement signals that can start behavior of knowledge integration. However, it would appear that the knowledge integration mechanisms relating to group problem solving are the most promising considering the context. From reviewing the literature it is possible to present three knowledge transfer mechanisms to bridge the knowledge gap between the contractors (projects) and the building product producers (products).

Focus Group: The knowledge integration mechanism of a focus group (group problem solving) could be used as a means of putting together project members from the construction sites with development staff from the building product producers. A focus group consists of a number of engaged individuals that discuss certain predefined problems. This group is normally administrated from the problem owner, in this cases the building product producers or facilitated by an independent facilitator.

A focus group can be beneficial in at least four different stages of the development process. First, to identify problems from a user/customer perspective, this could trigger new development projects through fresh ideas with a real need. As the building material companies are not represented at the sites there is a need for an inflow of ideas or problems from the sites. Secondly, in a problem solving situation, where the focus group can work on solving the problems identified in collaboration with the building product producer. Thirdly, it could be used in a test phase where ideas from the building product producer can be tested with the potential users/costumers. This could be ideas in more or less developed forms from sketches to prototype materials. Fourthly, the involvement of a focus group leads to the possibility of having some recommendations to use in the launch of a new product.

Idea Box: The mechanism of an idea box could be implemented physically or virtually through the work site (physical box) or within the construction team (virtually). This could be classified as a rule and directive in the case of virtual solution, but is leaning towards being a routine as the building product producer cannot make it mandatory to hand in ideas. This would be difficult to achieve without some form of contractual condition and support from project managers.

Pre-launch routines: Related to the idea box is the practical pre-launch routine, where the project team makes a formal attempt to interact with the building product producers (or vice-versa). This is akin partnering and relational forms of contracting; the idea being to bring the producers into the project environment. The challenge here relates to the type of procurement route being used and the willingness of all project actors to collaborate.

\section{REFERENCES}

[1] Druker, P.F. (1985) Innovation and Enterpreneurship: practice and principles, William Heinemann, London.

[2] Utterback, J.M. (1994) Mastering the Dynamics of Innovation, Harvard Business School Press, Boston, M.A.

[3] Davies, S. (1979) The Diffusion of Process Innovations, Cambridge University Press, Cambridge.

[4] Akintoye, A., Goulding, J. and Zawdie, G. (Eds.) (2012) Construction Innovation and Process Improvement, Wiley-Blackwell, Chichester.

[5] Ball, M. (1988) Rebuilding Construction: economic change in the British construction industry, Routledge, London.

[6] Cigén, S. (2003) Materialleverantören i byggprocessen, Licentiate Thesis 2003:69 Luleå University of Technology.

[7] Larsson, B. (1992) Adoption av ny produktionsteknik på byggarbetsplatsen. Report 30. Institutionen för byggnadsekonomi, Chalmers, Göteborg. 
[8] Larsson, B., Sundqvist, J. and Emmitt, S. (2006) Component Manufacturer's Perceptions on Managing Innovation, Building Research \& Information 34(6) pp. 552-564.

[9] Sundqvist, J. (2004) Low innovation among the building material manufacturers: the natural level of the trade, The Australian Journal of Construction and Building Economics, Vol 4, nr 1.

[10] Sundqvist, J., Larsson, B., and Lindahl, G. (2007) Cooperation in the building sector between building- material manufacturers and contractors to develop products, The Australian Journal of Construction Economics and Building 7(2), pp. 46-54.

[11] Emmitt, S. and Yeomans, D.T. (2007) Specifying Buildings: a design management perspective (2nd Edition), Butterworth-Heinemann, Oxford.

[12] Kanji, G.K. \& Wong, A. (1998) Quality culture in construction industry, Total Quality Management, 9 (4 \& 5), pp. S133-S140.

[13] Milakovich, M.E. (1995) Improving Service Quality: Achieving High Performance in the Public and Private Sectors, St. Lucie Press, FL.

[14] Sommerville, J. (1994) Multivariate barriers to total quality management within the construction industry, Total Quality Management, 5, pp. 289-298.

[15] Eccles, R. G. (1981) Bureaucratic versus craft administration: The relationship of market structure to the construction firm. Administrative Science Quarterly 26(3) 449-469.

[16] Dubois, A. and Gadde, L-E. (2002) The Construction industry as a loosely coupled system: implications for productivity and innovation. Construction Management and Economics 20, 621623.

[17] Rowlinson, S.M. \& Walker, A. (1995) The Construction Industry in Hong Kong, Longman, Hong Kong.

[18] Emmitt, S. (1997) 'The diffusion of innovations in the building industry', PhD thesis, University of Manchester.

[19] Gann, D. (2000) Building Innovation. Thomas Telford, London.

[20] Winch, G. (2003) How innovative is construction? Comparing aggregated data on construction innovation and other sectors - a case of apples and pears. Construction Management and Economics 21(6), pp. 651-654.

[21] SOU 2002:115 (2002) The Swedish Building Commission, Skärpning gubbar! - Om konkurrensen, kostnaderna och kompetensen i byggsektorn.

[22] Bowley, M. (1960) Innovations in Building Materials: an economic study, Gerald Duckworth \& Co., London.

[23] Slaughter, E.S. (2000) Implementation of construction innovations, Building Research and Information, 28(1), 2-17.

[24] Rogers, E.M. (2003) Diffusion of Innovations (5th edition), Free Press, New York.

[25] Lutz, J. and Gabrielsson, E. (2002) Byggsektorns struktur och utvecklingsbehov, Byggkommissionen, Stockholm.

[26] Erhvervsfremme Styrelsen (2001) Byggevareleverandørernes rolle I byggeriets udvikling. Erhvervsministeriet, Copenhagen.

[27] Department of Trade and Industry (2002) Construction Products -Structural Conduct and Performance Study.

[28] Lin, B., Chen, C. (2006) Featuring product innovation in industry networks: the mediating role of knowledge integration. International Journal of Human Resource Management 17 (1) 155-173.

[29] Tell, F. (2011) Knowledge integration and innovation: A survey of the literature. In: Berggren, C., Bergek, A., Bengtsson, M., Hobday, L., Söderlund, J. (Eds.), Knowledge Integration and Innovation: Critical Challenges Facing International Technology-based Firms, Oxford University Press, Oxford.

[30] Postrel, S. (2002) Islands of shared knowledge: specialization and mutual understanding in problem-solving teams. Organization Science 13 (3) 303-320.

[31] Enberg, C., Lindkvist, L., Tell, F., 2006. Exploring the Dynamics of knowledge integration Acting and Interacting in Project Teams. Management Learning 37 (2) 143-165. 
[32] Hoopes, D., Postrel, S. (1999) Shared Knowledge, 'Glitches', and Product Development Performance. Strategic Management Journal 20 (9) 837-865.

[33] Schmickl, C., Kieser, A.(2008) How much do specialists have to learn from each other when they jointly develop radical product innovations? Research Policy 37 (3) 1148-1163.

[34] Huang, J., Newell, S.(2003) Knowledge integration processes and dynamics within the context of cross-functional projects. International Journal of Project Management 21 (3) 167-176.

[35] Prencipe, A., Tell, F.(2001) Inter-project learning: processes and outcomes of knowledge codification in project-based firms. Research Policy 30 (9) 1373-1394.

[36] Li, T., Calantone, R. (1998) The Impact of Market Knowledge Competence on New Product Advantage: Conceptualization and Empirical Examination. Journal of Marketing 62 (4) 13-29.

[37] Stuart and Podolny (1996) Local Search and the Evolution of Technological Capabilities, Strategic Management Journal, Vol. 17, (Special Issue Summer), pp. 21-38.

[38] Kodama, M. (2009) Boundaries Innovation and Knowledge Integration in the Japanese Firm, Long Range Planning 42, 463-494

[39] Nesta, L., Saviotti, P.(2006) Firm knowledge and market value in Biotechnology. Industrial and Corporate Change 15 (4) 625-652.

[40] Becker, M. C. and Zirpoli. F. (2003) Organizing new product development: Knowledge hollowing-out and knowledge integration - the FIAT Auto case, International Journal of Operations \& Production Management Vol. 23 No. 9, pp. 1033-1061.

[41] Van de Ven, A.H., Delbecq A.L. and Koenig Jr, R. (1976) Determinants of coordination modes within organizations, American Sociological Review 41(2) pp. 322-338.

[42] Demsetz, H. (1991) 'The theory of the firm revisited'. The Nature of the Firm. New York: Oxford University Press, 159-78.

[43] Grant, R., 1996. Prospering in Dynamically-Competitive Environments: Organizational Capability as Knowledge Integration. Organization Science 7 (4) 375-387.

[44] Hofstede, G. H. (1980) Culture's Consequences: International differences in work-related values, Sage Publications, Thousand Oaks, CA.

[45] Hofstede, G.H. (2001) Culture's Consequences: comparing values, behaviours, institutions and organisations across Nations (2nd, Edition), Sage Publications, Thousand Oaks, CA. 
